\title{
The use of mobile phone-based interventions to support adherence to antiretroviral therapy in sub-Saharan Africa: is it acceptable, feasible and sustainable?
}

\author{
Authors: Juliet Babirye ${ }^{\mathrm{A}}$ and Tine Verdonck ${ }^{\mathrm{B}}$
}

\section{Background}

HIV/AIDS remains a challenge. Achieving the last $90 \%$ in UNAIDS' 90-90-90 targets - viral suppression - requires optimal adherence to antiretroviral treatment (ART). ${ }^{1}$

Mobile phone-based interventions (MPBIs) promote adherence. $^{2-7}$ Scale-up of these necessitates a wider appreciation of the beneficiaries' likes and values, and cost implications. This study reviews and summarises the literature on acceptability, feasibility and sustainability of MPBIs for improving ART adherence in sub-Saharan Africa.

\section{Methods}

This is a narrative review of the published literature that included elements of a systematic review process. ${ }^{8}$ The search strategy retrieved articles that combined 1) mobile phone use and 2) ART and 3) adherence and 4) sub-Saharan Africa. Findings are presented as a narrative synthesis.

\section{Results}

The included studies were conducted in seven countries. User subgroups including adolescents and pregnant women were included. The studies assessed short messages (SMS) and/or voice calls as reminders, or with additional messaging.

Regarding acceptability, patients found SMS and voice calls beneficial as reminders, tools for consultation and as conduits for encouragement. They would be most useful among those starting ART to help them get into a routine. Patients prefer two-way SMS to one-way SMS. The fear of breach of confidentiality is a major barrier.

Regarding feasibility, phone ownership was relatively high. Most participants could read and write SMS. There were conflicting concerns about the affordability. Technical challenges such as poor network, high mobile phone turnover and certain phone habits were barriers to feasibility.

On sustainability, information was very limited. Patients' concerns were related to SMS fatigue when they get bored and fear of dependency on the SMS, yet they were unsure about the longevity of SMS programmes.

Authors: ${ }^{A}$ Makerere University - Johns Hopkins University Research Collaboration, Kampala, Uganda; ${ }^{\text {B}}$ Institute of Tropical Medicine, Antwerp, Belgium

\section{Conclusion}

In promoting adherence, MPBIs are considered acceptable. Fear of breach of confidentiality is a major concern. Technical challenges and some individual phone habits are barriers. Information about costing and sustainability is limited and inconclusive. There are concerns about maintaining such interventions in the long term and addressing SMS fatigue among users. During scale-up, MPBIs could be prioritised for some patient groups among whom they would be most useful, such as those starting ART.

\section{Conflicts of interest}

None declared.

\section{References}

1 Joint United Nations Programme on HIV/AIDS. Start free stay free AIDS free - 2017 progress report. Geneva: UNAIDS, 2018. www. unaids.org/en/resources/documents/2018/start-free-stay-free-aidsfree-2017-progress-report [Accessed 10 December 2019].

2 Mills EJ, Lester R, Thorlund $\mathrm{K}$ et al. Interventions to promote adherence to antiretroviral therapy in Africa: a network meta-analysis. Lancet HIV 2014:1:e104-11.

3 Kanters S, Park JJH, Chan K et al. Interventions to improve adherence to antiretroviral therapy: a systematic review and network meta-analysis. Lancet HIV 2017;4:e31-40.

4 Mbuagbaw L, van der Kop ML, Lester RT et al. Mobile phone text messages for improving adherence to antiretroviral therapy (ART): an individual patient data meta-analysis of randomized trials. BM] Open 2013:3:e003950.

5 Finitsis DJ, Pellowski JA, Johnson BT. Text message intervention designs to promote adherence to antiretroviral therapy (ART): a metaanalysis of randomized controlled trials. PLoS One 2014;9:e88166.

6 Horvath T, Azman H, Kennedy GE, Rutherford GW. Mobile phone text messaging for promoting adherence to antiretroviral therapy in patients with HIV infection. Cochrane Database Syst Rev 2012:CD009756.

7 Wald DS, Butt S, Bestwick JP. One-way versus two-way text messaging on improving medication adherence: a meta-analysis of randomized trials. Am J Med 2015;128:1139.e1-5.

8 Grant MJ, Booth A. A typology of reviews: an analysis of 14 review types and associated methodologies. Health Info Libr J 2009;26:91-108. 